\title{
A Probabilistic Strategy for Compositing Samples for Waste Analysis
}

by

W. G. Winn

E. I. du Pont de Nemours and Company

Savannah River Site

Aiken, South Carolina 29808

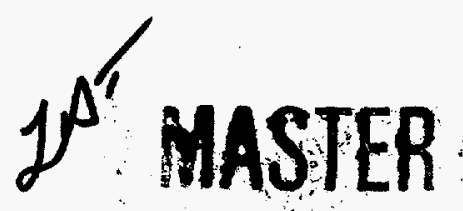

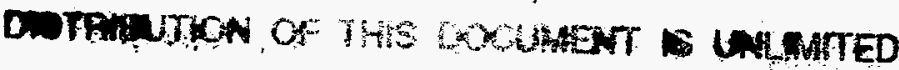

DOE Contract No.

This paper was prepared in connection with work done under the above contract number with the U.S.

Department of Energy. By acceptance of this paper, the publisher and/or recipient acknowledges the U.S.

Government's right to retain a nonexclusive, royalty-free license in and to any copyright covering this paper, along with the right to reproduce and to authorize others to reproduce all or part of the copyrighted paper. 


\section{DISCLAIMER}

This report was prepared as an account of work sponsored by an agency of the United States Government. Neither the United States Government nor any agency thereof, nor any of their employees, makes any warranty, express or implied, or assumes any legal liability or responsibility for the accuracy, completeness, or usefulness of any information, apparatus, product, or process disclosed, or represents that its use would not infringe privately owned rights. Reference herein to any specific commercial product, process, or service by trade name, trademark, manufacturer, or otherwise does not necessarily constitute or imply its endorsement, recommendation, or favoring by the United States Government or any agency thereof. The views and opinions of authors expressed herein do not necessarily state or reflect those of the United States Government or any agency thereof.

This report has been reproduced directly from the best available copy.

Available to DOE and DOE contractors from the Office of Scientific and Technical Information, P. O. Box 62, Oak Ridge, TN 37831; prices available from (423) 576-8401.

Available to the public from the National Technical Information Service, U. S. Department of Commerce, 5285 Port Royal Road, Springfield, VA 22161. 


\section{DISCLAIMER}

Portions of this document may be illegible in electronic image products. Images are produced from the best available original document. 


\section{A PROBABILISTIC STRATEGY FOR COMPOSITING SAMPLES FOR WASTE ANALYSIS}

by

W. G. Winn

Westinghouse Savannah River Company Savannah River Site Aiken, SC 29808

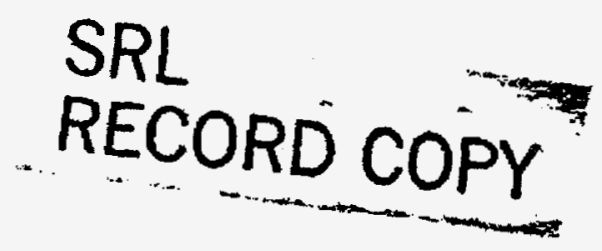

\section{INFORMATION ONLY}

This paper was prepared in connection with work done under Contract No. DE-AC09-76SR00001 (now Contract No. DE-AC09-88SR18035) with the U.S. Department of Energy. By acceptance of this paper, the publisher and/or recipient acknowledges the U.S. Government's right to retain a nonexclusive, royalty-free license in and to any copyright covering this paper, along with the right to reproduce and to authorize others to reproduce all or part of the copyrighted paper. 


\section{A PROBABILISTIC STRATEGY FOR COMPOSITING SAMPLES FOR WASTE ANALYSIS}

by

W. G. Winn

Westinghouse Savannah River Company

Savannah River Site

Aiken, SC 29808

\section{ABSTRACT}

A probabilistic strategy for sample compositing was developed to minimize the volume of waste sample analyses. Disposable waste must have a contaminant concentration below an acceptance limit $\mathrm{L}$. A composite of $\mathrm{N}$ different samples must have a contaminant concentration below $L / N$, to assure that no individual sample is unacceptable. Unacceptable samples are eventually identified by analyses of successive splits composited with N/2,N/4, ..of the original samples. The probable number of such analyses is derived using conservative log-Normal distributions to model the concentration probabilities. A minimum number of analyses result when $\mathrm{N} \approx \mathrm{L} / \mathrm{a}$, where a is the average contaminant concentration expected for the sample. The approximation is useful for $L / a \geq 5$. Experimental composites from 880 samples with $L / a=41.8$ are consistent with the calculated predictions.

The information contained in this article was developed during the course of work under Contract No. DE-AC09-76SR00001 (now Contract No. DE-AC09-88SR18035) with the U.S. Department of Energy. 


\title{
A Probabilistic Strategy for Compositing \\ Samples for Waste Analysis
}

\author{
Willard G. Winn \\ Westinghouse Savannah River Company \\ Savannah River Site \\ Aiken, SC 29808
}

\section{INTRODUCTION}

Because of the growing emphasis on waste disposal impact to the environment, the analysis volume for waste samples has increased dramatically in recent years. At the Savannah River Site, the demand for establishing acceptable radionuclide levels for offplant waste disposal has resulted in strategies for compositing samples to help alleviate the analysis load. A strategy based on probabilistic methods is examined; it should have broad application in areas of waste certification. This method is a variation of sequential statistical analysis $(1,2)$, which minimizes the required measurements in batch appraisals.

\section{THEORY}

General Method. Environmental standards for waste typically require that the contaminant concentration, c, be below some limit, L. Normally, the contents of waste containers are homogenized, and then individual samples are taken and analyzed. If $\mathrm{N}$ waste samples from different containers are equally mixed as a single composite sample, this sample must have $\mathrm{c}<$ $L / N$, to ensure that no individual component sample of the composite contains the entire contamination at a level exceeding $L$. If measurements on any composite sample yielded $c>L / N$, then two recomposites would be made, each from a different $\mathrm{N} / 2$ samples included in the original composite. Each of these recomposites would be tested against the criteria that $c<L / N / 2]$ or $c$ $<2 \mathrm{~L} / \mathrm{N}$. This recompositing process would continue as necessary, until (1) all recomposites have satisfied $c<2 \mathrm{~L} / \mathrm{N}=\mathrm{L}_{\mathrm{j}}$ at some $\mathrm{jth}$ recomposite level and (2) any individual component samples 
with $c>L$ have been identified. Because each recomposite will split the preceding composite by a factor of 2 , it is recommended that $N=2^{n}$, where $n$ is an integer. With this choice of $N$ the $j$ th recomposite limit is given by

$$
L_{j}=2^{j-n} L
$$

This recompositing scheme requires some knowledge of the probabilities of exceeding the limits $L_{j}$, to project how many sample analyses are needed for a given $N$. Suppose some large number of samples,S, must be appraised relative to compliance with the limit $L$. Then, the initially composited samples will require $A_{o}$ analyses, as given by

$$
A_{o}=S / N=2^{-n} S
$$

A total of $A_{0} P\left(c_{0}>L_{0}\right)$ analyses would fail the compliance criteria, requiring analysis of $A_{1}$ recomposited samples, which are composed of paired splits from the first composites. Here, $P\left(c_{0}>L_{0}\right)$ is the probability that an initial composite sample has $c_{0}>L_{0}$. More explicitly, $A_{1}$ is given by

$$
\begin{aligned}
A_{1} & =2 A_{0} P\left(c_{0}>L_{0}\right) \\
& =2^{1-n} S P\left(c_{0}>L_{0}\right)
\end{aligned}
$$

Continuing this procedure, it is readily observed that the number $A_{j}$ of $j$ th recomposite analyses will be given by

$$
\begin{aligned}
A_{j} & =2 A_{j-1} P\left(c_{j-1}>L_{j-1}\right) \\
& =2^{j-n} S \underset{i=1}{\pi} P\left(c_{i-1}>L_{j-1}\right)
\end{aligned}
$$


Thus, the total number $A$ of expected analyses is obtained by summing the $A_{j}$, viz

$$
A=\sum_{j=0}^{n} A_{j}
$$

where in summary

$$
\begin{aligned}
& A_{j}=2^{j-n} S \underset{i=0}{\pi} P_{i} \\
& \begin{aligned}
P_{i} & =1 \text { for } i=0 \\
& =P\left(c_{i-1}>L_{i-1}\right) \text { for } i>0
\end{aligned} \\
& L_{i}=2^{i-n} L
\end{aligned}
$$

Probability Assignment . The preceding treatment defines the general formalism; however, the probabilities $P_{1}$ must be defined to obtain results. These probabilities may be deduced from measurements; however, it is desirable to have useful guidelines before detailed probability data are developed. It will be shown that log-Normal distributions provide reasonable estimates of the $P_{i}$.

In general, waste is expected to be generated from a variety of sources with contamination levels, $\mathrm{c}$, that depend on numerous multiplicative factors which are randomly distributed. As a statistical variable, $\mathrm{c}$ is given as

$$
c=X_{1} X_{2} X_{3} \ldots . . . X_{k}
$$

where each $\mathrm{X}_{\mathrm{i}}$ is a randomly distributed factor of a large total of $\mathrm{k}$ factors. By taking the $\log$ of both sides of the equation

$$
\log (c)=\sum_{i=1}^{k} \log \left(X_{i}\right)=\sum_{i=1}^{k} Y_{i}=k\left[\sum_{i=1}^{k} Y_{i} / k\right]
$$


Here the $Y_{i}$ are also randomly distributed and their sum or average should be distributed as a Gaussian distribution, according to the Central Limit Theorem (3). Thus, $\log (c)$ also has a Gaussian distribution, and accordingly $\mathrm{c}$ has a log-Normal distribution.

An initial trial $\log$-Normal distribution for $c$ can be approximated with data from preliminary analyses. A conservative approximation, which uses larger $P_{i}$, should be favored. The present work assumes an average $c=a$ is available but that the sigma $s$ is unknown. Conservatively assuming that $s$ is comparable to the average $c$, a value of $s=a$ is assigned. Corresponding log-Normal parameters are derived as

$$
\begin{aligned}
\text { Log concentration } & =\log (\mathrm{c})=\mathrm{x} \\
\text { Log-Normal average } & =\log (\mathrm{a})=\mathrm{u} \\
\text { Log-Normal sigma } & =\log (\mathrm{a}+\mathrm{s})-\log (\mathrm{a})=\log (2)
\end{aligned}
$$

Thus, for this conservative case, the probabilities may be written as

$$
\begin{aligned}
P_{i}=1 \text { for } i=0 & \\
P_{i}=P\left(c_{i-1}>L_{i-1}\right) & =G\left(x>\log L_{i-1}\right) \text { for } i>0 \\
& =G\left(x-u>\log \left[L_{i-1} / a\right]\right) \\
& =G(Z>\log [L / a] / \log [2]+i-n-1)
\end{aligned}
$$

where $G\left(Z>Z_{L}\right)$ is the integrated Gaussian probability for $Z>Z_{L}$, and the $Z$ values are normalized to the standard deviation (i.e., $Z=[x-u] / \log [2]$ ). No distinction has been made between the $c_{f}$ and $c$, which is also a conservatism because the distributions of sample composites should be narrower than those of individual samples.

\section{CALCULATIONS AND MEASUREMENTS}

A BASIC code COMPOSE was written to calculate the projected number of analyses A from Equation 5, using the conservative log-Normal probability estimates of Equation 9. 
Calculation of $A$ is straight forward, once the $P_{i}$ are determined. The $P_{i}$ are determined by interpolation of 5-place Gaussian data which are encoded (4).

Figure 1 plots $A$ vs $N\left(\right.$ or $2^{\mathrm{n}}$ ) for various $L / a$ values. The $A$ analyses are expressed in percent of total samples $S$. The $L / a$ range is from 0 to 50 . For $L / a=0$, all $P_{i}=1$ and this represents the worst possible situation. The plots indicate that there is no advantage in compositing samples for $L / a \leq 2$, as all analyses yield $A$ 's that exceed $100 \%$ of the total samples $S$. For $L / a \geq 5$ compositing does become noticeably advantageous, and an optimum choice of $\mathrm{N}$ can be selected. Here, as $N$ increases from 1 , a minimum $A$ is reached near $N \approx L / a$; then $A$ rises very little as $N$ increases further. This shows that $\mathrm{N}$ must only exceed some minimum value to yield a nearoptimum A; however, Figure 2 illustrates that it is ridiculous to use arbitrarily large $N$. In this figure, $P_{1}$ for the first recomposite is plotted against $N$; for higher $N$ values $P_{1}$ approaches 1 , and thus it is ridiculous to analyze composite samples that are virtually assured of being recomposited. Thus, an $\mathrm{N}$ that corresponds to both low $\mathrm{A}$ and low $\mathrm{P}_{1}$ is preferred, and this occurs near the minimum A value deduced from Figure 1.

COMPOSE can print all $A_{j}$ and $P_{1}$ values corresponding to an $A$ calculation. These results illustrate that $P_{1}>P_{2}>\ldots .>P_{n}$, and that each of these probabilities also increases toward 1 as $N$ increases beyond its optimum value. Figure 3 illustrates this behavior for $L / a=41.8$, which corresponds to experimental data discussed next.

Composite data from a recent radioassay for paint/solvent waste serve to illustrate the usefulness of the method. In this work, the total radioactive concentration for the paint/solvent waste had to be less than $\mathrm{L}=2 \mathrm{nCi} / \mathrm{g}$ to comply with DOT regulations for offplant shipment (5). Here, $S=880$ drums of liquid waste were sampled and composited as 44 samples, each with $N=$ 20 drum samples per composite. Of these, $A_{1}=4$ and $A_{2}=2$ recomposite analyses were required. A geometric mean of the samples was $0.0478 \mathrm{nCi} / \mathrm{g}$, yielding $\mathrm{L} / \mathrm{a}$ of 41.8 . Table I shows that results for the experimental data are reasonably consistent with the calculated projections. 
In this comparison, an experimental $\mathrm{N}=20 \neq 2^{\mathrm{n}}$ is used, and the corresponding calculated values are interpolated using Figure 3 and Equation 4. Ideally $N=2^{n}$ should have been selected for the analyses, and subsequent work is now incorporating such N. As these subsequent measurements evolve into comparably large data sets (e.g., $S \approx 1000$ ), additional appraisals will be made.

\section{SUMMARY}

These studies show that a probabilistic approach is useful in predicting sample compositing strategies for waste certification. The conservative log-Normal probability assignments are useful as initial guidelines for the compositing strategy, as evidenced by comparison with the experimental data in Table I. Even though the calculations project a somewhat larger number of analyses than observed in the experimental measurements, the compositing strategies deduced from either calculations or experiment are comparable.

Some simplified general guidelines can be derived from the conservative calculations plotted in Figures 1 and 2. These plots demonstrate that $\mathrm{N}=\mathrm{N}_{\mathrm{m}}=2^{\mathrm{m}} \approx \mathrm{L} / \mathrm{a}$ corresponds to the minimum number $A$ of analyses, for $L / a \geq 5$. Mathematically, the value of $N_{m}$ can be determined as

$$
N_{m}=2^{m}=2^{\operatorname{loctgag}[\log ([/ / 2) \log (2)+0.5]}
$$

or $N_{m}$ is the factor of 2 nearest L/a. Typically, this optimum $N_{m}$ yields $P_{1} \approx 0.5$, although this conservative log-Normal treatment causes this value to be somewhat high. However, because such a large $P_{1}$ can require a fair amount of bookkeeping for addressing sample recompositing, it may be wise to select $N=2^{m-1,}$ where $P_{1} \approx 0.15$ and the corresponding $A$ is only slightly above the optimum value. A choice of $N=2^{m-2}$ yields a very low $P_{1} \approx 0.03$; however, the corresponding $A$ is noticeably greater. 
The data of Table I provide an example of this guideline. Equation 10 projects $N_{m}=32$ from the experimental $L / a$ of 41.8 , but with corresponding $P_{1}=0.350$. With $N=2^{\text {tri-1 }}=16$, the $P_{t}$ is reduced to 0.083 . Thus, the experimental choice of $\mathrm{N}=20$ is quite reasonable as it projects $P_{1}=0.135$; however, as mentioned earlier, an $N=2^{n}$ should be favored when possible.

These considerations identify the variables that must be appraised in selecting a compositing strategy. It is likely that more accurate (less conservative) probability assignments can be modeled into the analysis as data for specific types of waste are developed. However, the present conservative model can always offer a general method for selecting an initial compositing strategy.

\section{ACKNOWLEDGMENTS}

W. L. McDowell, C. D. Ouzts, and the author performed the experimental measurements in a separate project. The author also acknowledges productive discussions with $\mathrm{K}$. J. Hofstetter and R. W. Taylor.

\section{REFERENCES}

1. G. B. Wetherill, Sequential Methods in Statistics, Spottiswoode Ballantyne, Colchester (England), 1966.

2. A. Wald, Sequential Analysis, John Wiley \& Sons, New York, 1947.

3. K. V. Bury, Statistical Methods in Applied Science, John Wiley \& Sons, London, 1974.

4. F. J. Wall, Statistical Data Analysis Handbook, McGraw Hill, New York, 1986.

5. Code of Federal Regulations, 49 CFR 173.403(g), June 1986. 
Table I. Comparison of Calculations and Measurements

Data are for $S=880$ paint/solvent waste-drum samples grouped as $\mathrm{S} / \mathrm{N}$ initial composites. The experimental average concentration of $\mathrm{a}=0.0478 \mathrm{nCi} / \mathrm{g}$ is compared to an $\mathrm{L}=2.0 \mathrm{nCi} / \mathrm{g}$, yielding $\mathrm{L} / \mathrm{a}=41.8$.

$$
\mathrm{N}=16
$$

calculated

A

$\mathrm{A}_{0} \quad \mathbf{5 5 . 0 0 0}$

$A_{1}$

$A_{2}$

$A_{3}$

$\mathrm{A}_{4}$

$A_{s}$

$A_{5}$

$\begin{array}{ll}\mathrm{P}_{0} & 1.00000 \\ \mathrm{P}_{1} & 0.08310 \\ \mathrm{P}_{2} & 0.00857 \\ \mathrm{P}_{3} & 0.00036 \\ \mathrm{P}_{4} & 0.00000 \\ \mathrm{P}_{5} & - \\ \mathrm{P}_{6} & -\end{array}$

$\mathrm{N}=20$

calculated $^{\mathrm{a}}$

$$
\mathrm{N}=32
$$

calculated

$\mathrm{N}=64$

calculated

$\begin{array}{cccr}56.356 & 50 \pm 3 & 50.007 & 50.278 \\ & & & \\ 44.000 & \equiv 44 & 27.500 & 13.750 \\ 11.880 & 4 \pm 2 & 19.252 & 20.087 \\ 0.475 & 2 \pm 2 & 3.200 & 14.063 \\ 0.001 & 0 & 0.055 & 2.337 \\ 0.000 & 0 & 0.000 & 0.040 \\ - & - & 0.000 & 0.000 \\ - & - & - & 0.000\end{array}$

$\begin{array}{cccc}1.000 & \equiv 1.000 & 1.00000 & 1.00000 \\ 0.135 & 0.045 \pm 0.017 & 0.35004 & 0.73045 \\ 0.020 & 0.250 \pm 0.250 & 0.08310 & 0.35004 \\ 0.001 & 0.0 & 0.00857 & 0.08310 \\ 0.000 & 0.0 & 0.00036 & 0.00857 \\ - & - & 0.00000 & 0.00036 \\ - & - & - & 0.00000\end{array}$

a Values are interpolated using calculations from Figure 3 and Equation 4.

b Experimental measurement errors are estimated as follows:

- $2 \pm 1$ composites of 44 needed to be recomposited for $4 \pm 2$ analyses, and yield $P_{1}=(2 \pm 1) / 44$.

- $1 \pm 1$ recomposites from 4 needed to be recomposited for $2 \pm 2$ analyses, and yield $\mathrm{P}_{2}=(1 \pm 1) / 4$.

- Error in $A$ accumulates from $A_{i}$ errors.

- The adoption of \pm 1 for each recomposite number is approximated from small number Poisson statistics. 
FIGURE 1. Sample analyses $A$ for $S=100 \%$ samples when first composites have $N=2^{n}$ samples each, for various limit/average ratios $\mathrm{L} / \mathrm{a}$. Conservative log-Normal probabilities are used.

FIGURE 2. First recomposite probability $P_{1}$ when first composites have $N=2^{n}$ samples each, for various limit/average ratios L/a. Note also that the minimum analyses $A$ for $\mathbf{n}=\mathbf{m}$ situations are identified. Conservative log-Normal probabilities are used.

FIGURE 3. Dependence of $i$ th recomposite probability $P_{i}$ on initial samples $N=2^{n}$ composited, for limit/average ratio $\mathrm{L} / \mathrm{a}=41.8$. 


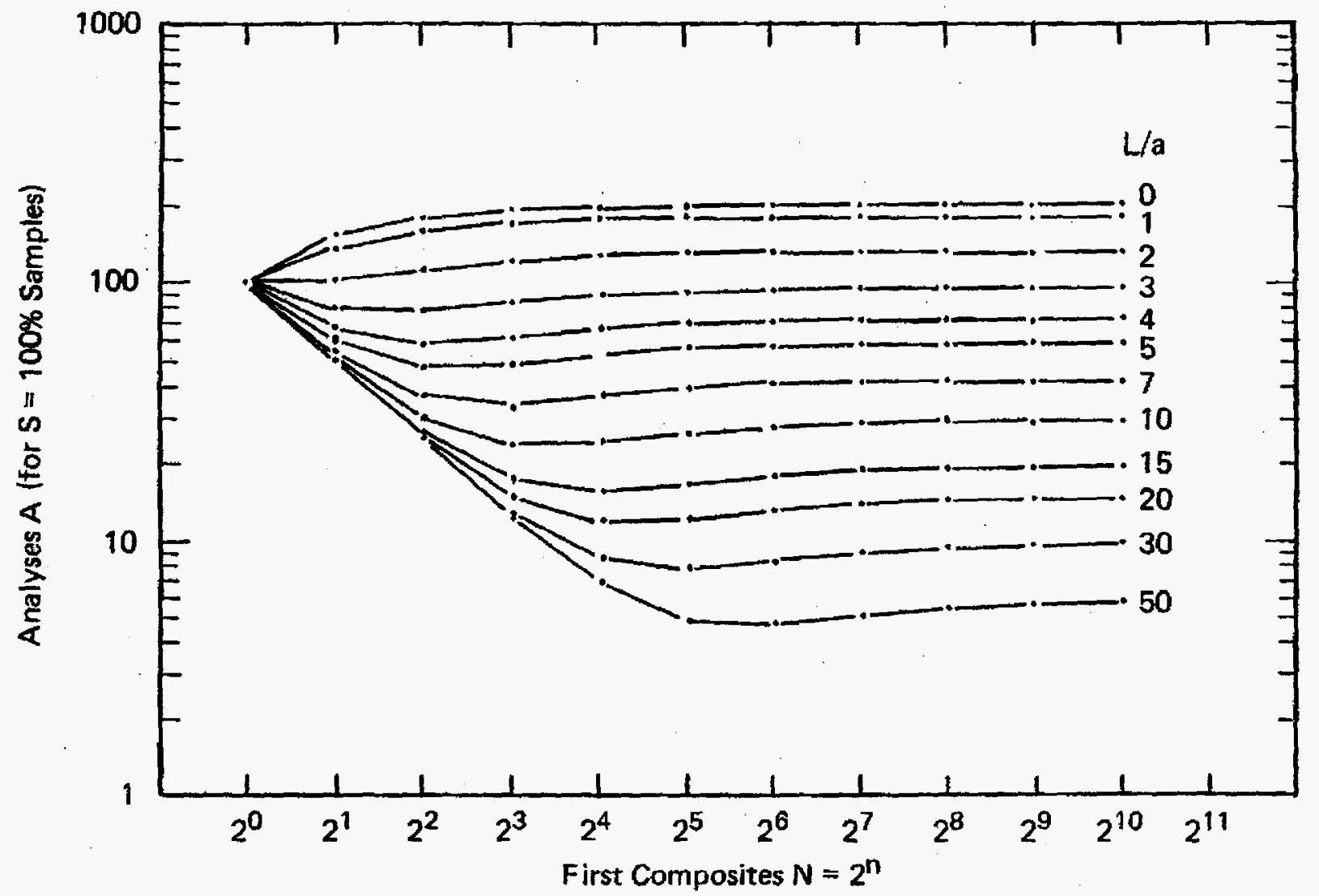




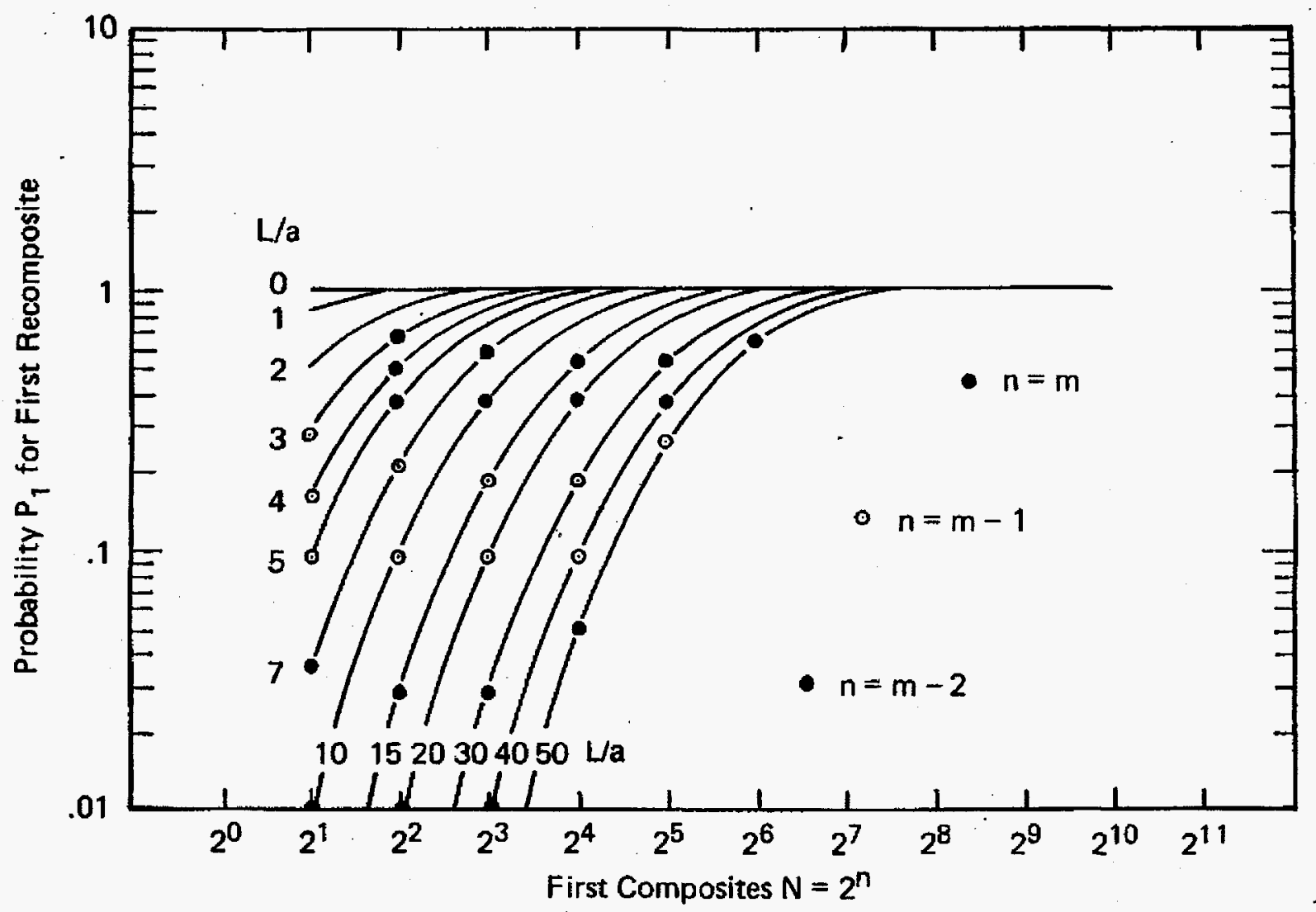




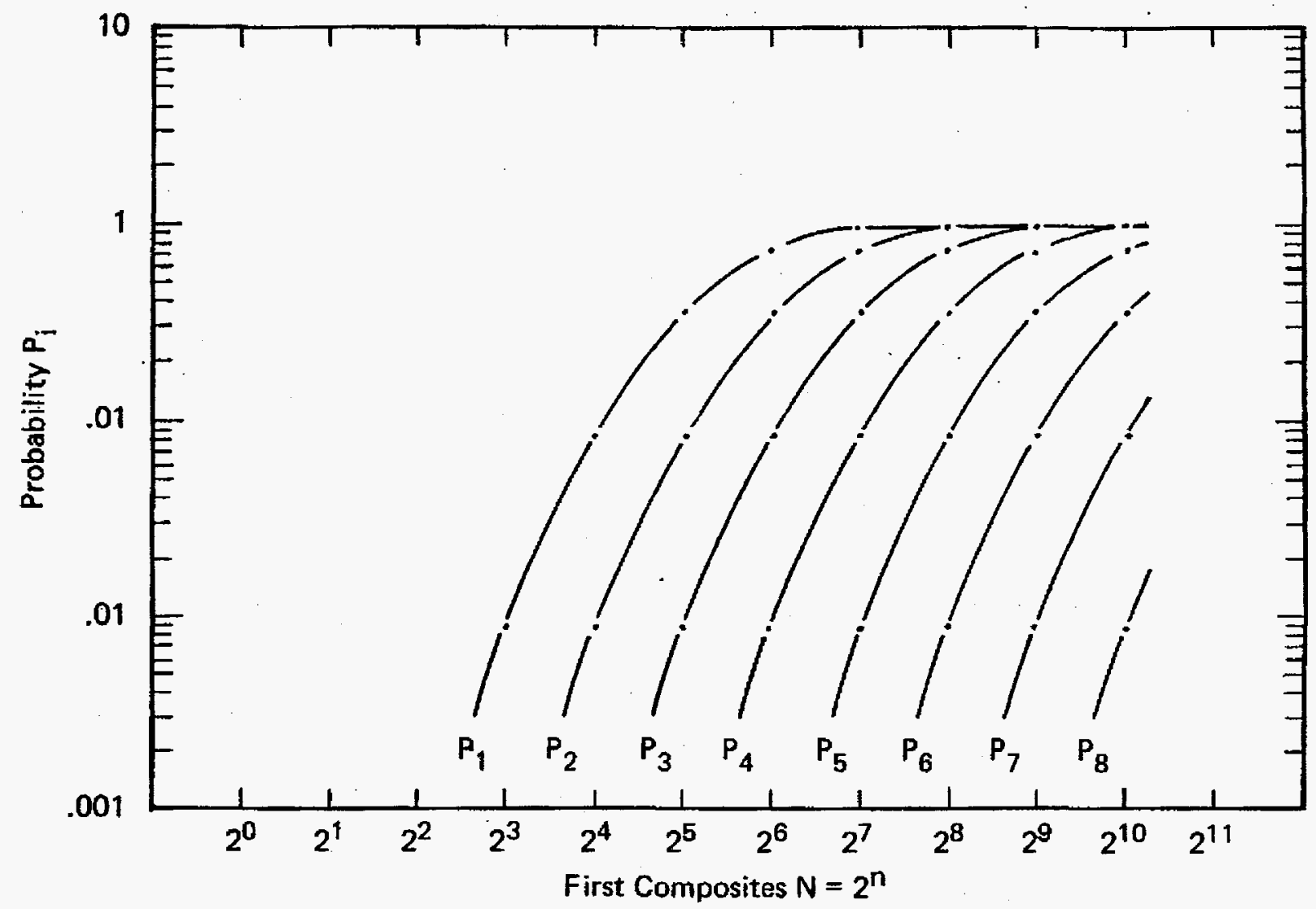

